\title{
Natal-Host Environmental Effects on Juvenile Size, Transmission Success, and Operational Sex Ratio in the Entomopathogenic Nematode Steinernema carpocapsae
}

\author{
Author(s): M. O. Therese and F. Bashey
}

Source: Journal of Parasitology, 98(6):1095-1100. 2012.

Published By: American Society of Parasitologists

URL: http://www.bioone.org/doi/full/10.1645/GE-3069.1

BioOne (www.bioone.org) is a nonprofit, online aggregation of core research in the biological, ecological, and environmental sciences. BioOne provides a sustainable online platform for over 170 journals and books published by nonprofit societies, associations, museums, institutions, and presses.

Your use of this PDF, the BioOne Web site, and all posted and associated content indicates your acceptance of BioOne's Terms of Use, available at www.bioone.org/page/terms_of use.

Usage of BioOne content is strictly limited to personal, educational, and non-commercial use. Commercial inquiries or rights and permissions requests should be directed to the individual publisher as copyright holder. 


\title{
NATAL-HOST ENVIRONMENTAL EFFECTS ON JUVENILE SIZE, TRANSMISSION SUCCESS, AND OPERATIONAL SEX RATIO IN THE ENTOMOPATHOGENIC NEMATODE STEINERNEMA CARPOCAPSAE
}

\author{
M. O. Therese and F. Bashey* \\ Indiana University, 1001 E. Third Street, Bloomington, Indiana 47405. e-mail: fbasheyv@indiana.edu
}

\begin{abstract}
Trans-host effects can alter the ecological and evolutionary dynamics of parasite and host populations. Here, we examine whether resource limitation within a parasite's natal host affects propagule size and influences parasite fitness in a new host. To alter resource competition, we infected caterpillars with 3 doses of the nematode Steinernema carpocapsae and harvested transmission-stage juveniles either early or late in the infection. We measured the size of these juveniles, and then we examined their ability to colonize and their sex ratio upon maturity in a new host. We found a trade-off between the cumulative number and size of nematodes emerging from a host. Emerging nematode size declined significantly over the time course of the infection, but dose had no significant effects. Larger, early emerging nematodes had greater success in colonizing a new host than smaller, later emerging nematodes, independently of whether they needed to locate the host. Furthermore, although early emerging nematodes resulted in an equal sex ratio in the new host, late emerging nematodes resulted in female-biased populations. These transmission and sex-ratio effects demonstrate that conditions in the natal host can affect parasite fitness, and they suggest that trans-host effects need to be more fully integrated into our studies of parasite populations.
\end{abstract}

For many species, the more offspring produced by a mother, the smaller the individual offspring will be due to allocation of limited resources (Lack, 1947; Smith and Fretwell, 1974). Offspring size versus number trade-offs have been reported for a wide array of species ranging from arthropods (reviewed in Fox and Czesak, 2000) to plants (e.g., Jakobsson and Eriksson, 2000) and vertebrates (e.g., Fleming and Gross, 1990; Mappes and Koskela, 2004). This trend also can be seen on a population level, as increased population density can lead to smaller average size of individuals due to competition for limited resources (e.g., Wall and Begon, 1987). These effects on size can influence both ecological and evolutionary dynamics, because size is a major determinant of fitness. For example, larger offspring size can correlate with greater reproductive output, greater survival, or both (Stanton, 1984; Einum and Fleming, 2000a). Similarly, increased population density can lead to smaller adult size, causing decreased fecundity, survival, or both (Hirschberger, 1999; Eitam et al., 2005).

In addition, males and females may differentially respond to a competitive environment. For example, high conspecific densities of the mosquito Aedes aegypti results in males maintaining developmental time but emerging as smaller adults, whereas females have a prolonged developmental time and maintain adult body size (Bedhomme et al., 2003). Population density also has been shown to shift sex ratio in response to competition. The sexratio shift may be a secondary effect, where one sex outcompetes the other sex and thus has greater survival (e.g., Cipollini, 1991), or there may be a change in the primary sex ratio where more of one sex is produced in response to conspecific densities (e.g., Nagelkerke and Sabelis, 1998).

Although the above-mentioned examples are of free-living organisms, these relationships also apply to parasitic organisms. Trade-offs between offspring size and number have been seen across parasite species (Loker, 1983; Poulin, 1995), and although rarely examined, within species as well (Herreras et al., 2007). More commonly, density or crowding is seen to reduce the size, fecundity, or both of individuals within a given host (Sandland

Received 20 December 2011; revised 21 May 2012; accepted 4 June 2012.

* To whom correspondence should be addressed.

DOI: $10.1645 / G E-3069.1$ and Goater, 2000; Ryder and Griffin, 2002; Milonas, 2005). As in free-living species, these competitive effects may affect the sexes differently (Zervos, 1988; Lowrie et al., 2004) or result in sex-ratio shifts (Izraylevich and Gerson, 1996; Lebreton et al., 2010). However, of special importance in parasites is how these competitive effects affect the success of parasite transmission to and establishment within new hosts. Indeed, such trans-host effects have been found in parasitic worms, as high density within an intermediate host can reduce parasite size, in turn, affecting parasite survival and fecundity in the definitive host (Steinauer and Nickol, 2003; Fredensborg and Poulin, 2005). Despite these studies, the generality of trans-host effects has not been established, nor fully integrated into our understanding of ecological and evolutionary dynamics of host-parasite interactions (Tseng, 2006; Little et al., 2007).

Here, we use the entomopathogenic nematode Steinernema carpocapsae to examine the effect of resource limitation on individual size and to determine the impact size has on the ability to locate, invade, and sexually mature within a new host. Transmission in this species occurs via a developmentally dormant, non-feeding infective juvenile (IJ) stage. IJs enter an insect larva and cause its death, usually within $48 \mathrm{hr}$. Within the host carcass, the nematodes mature and reproduce for 1 , or more, generations, until resources become depleted and a new generation of infective stage juveniles emerges, approximately a week after the initial infection. Increasing the infective dose can decrease the size of IJs emerging from a host (Selvan et al., 1993), and IJs that emerge later in the course of an infection are usually smaller than earlier emerging IJs (Nguyen and Smart, 1995). With this in mind, we varied both collection date and infective dose to create variation in IJ size. We also examined whether a trade-off between the size and cumulative number of infective offspring nematodes emerging from a host could be detected within this population. We then conducted fitness assays that tested either the ability of IJs to infect a host when placed in direct contact with it, or the ability to locate and infect a host placed $1.5 \mathrm{~cm}$ away. These assays allowed us to determine whether IJ size affects survival within a new host, and whether the size effect depends on the need to locate the host. Finally, we examined the sex ratio of the fitness assay 
survivors to determine whether natal-host effects differ between the sexes.

\section{MATERIALS AND METHODS}

\section{Study system}

Steinernema carpocapsae is a parasitic nematode that infects a broad range of insect and arthropod hosts (Peters, 1996). These nematodes, together with their symbiotic bacteria, are highly virulent parasites requiring the death of the insect host to successfully complete the life cycle. All life stages but the IJ-stage nematodes occur within the host or its carcass. Because the host dies soon after infection, the host environment forms a limited resource for the nematode population. IJs infect, sexually mature, and reproduce for 1 , or more, generations in the host carcass. Low food level and high nematode density cues the production of IJs (Popiel, 1989) that leave the depleted host carcass and enter the surrounding environment to seek a new host. As a non-feeding stage, the IJ nematodes are dependent on the resources they were able to acquire and store while within the host carcass for their free-living survival and subsequent establishment in a new host (Qui and Bedding, 2000a, 2000b). Because IJ resource levels are correlated with IJ size, here, we used IJ length as an indicator of IJ resource level.

Steinernema carpocapsae is broadly classified as an ambush forager (Campbell et al., 2003). Nevertheless, IJs can crawl effectively and can even jump several body lengths in distance in dispersing to a new host (Campbell and Gaugler, 1993; Campbell and Kaya, 1999). Late emerging IJs are better able to successfully colonize hosts than those emerging earlier (Lewis and Gaugler, 1994; Alsaiyah et al., 2009); however, whether this is related to their smaller size (Nguyen and Smart, 1995) has not been examined. In addition, there are conflicting reports in the literature on whether sex ratio varies over the course of an infection and whether the sexes differ in their ability to locate hosts (Grewal et al., 1993; Alsaiyah et al., 2009).

\section{Stocks}

The insect hosts used were larvae of the greater wax moth, Galleria mellonella, obtained from Buddy Bill's Bait Barn (Bloomington, Indiana). The nematodes used were from an outbred stock maintained in our laboratory. The stock was originally established from a mixture of 3 strains (All, Sal, and an unidentified strain) in 2004 and were propagated in $G$. mellonella for $>10$ passages by the start of the study at doses of $\leq 200$ IJs/caterpillar.

\section{Experimental manipulation of IJ size}

Individual G. mellonella hosts were infected at either a low (20 IJs), intermediate $(200 \mathrm{IJs})$, or high (400 IJs) dose. The normal life cycle of the nematode was allowed to progress and a week after infection, IJs began to emerge from the host carcass. The nematodes emerging on day 1 postemergence (early) and day 5 post-emergence (late) were counted, individually measured, and used in fitness assays.

The IJ size manipulation infections were performed in 3 blocks. Each block consisted of 30 hosts equally divided among the 3 dose treatments, for 90 hosts in total. Galleria mellonella larvae were weighed, individually placed in plastic petri dishes $(60 \mathrm{~mm} \times 20 \mathrm{~mm})$ lined with filter paper, and moistened to a total volume of $500 \mu \mathrm{l}$ of deionized water. The dose of nematodes (in deionized water) was applied directly onto the dorsum of each caterpillar host. After infection, hosts were incubated at $26 \mathrm{C}$. Host mortality was $100 \%$, usually within the first $48 \mathrm{hr}$ post-infection (PI). After death, hosts were moved to White traps (White, 1927; as modified by Bashey et al., 2007) for maintenance of the infection, desiccation prevention, and collection of emerging nematodes. One week PI, host cadavers were checked for emergence twice a day (morning and evening) until emergence of a new generation of IJs was seen.

Nematodes emerged from 85 of the 90 infected hosts. The offspring generation IJs were rinsed off the filter paper and stored in deionized water at $8 \mathrm{C}$ until they could be counted, photographed, and used in infectivity assays. The IJs emerging from a host in the first $24 \mathrm{hr}$ post-emergence were collected in the White trap as day 1 (early) emergence. After this 24-hr period, the host was moved to a new White trap, and IJs were allowed to emerge for $72 \mathrm{hr}$ and collected in White traps for days 2-4. The host was moved to a third White trap and nematodes emerging over the next $24-\mathrm{hr}$ period were collected as day 5 (late) emergence. Each of the 3 collections were counted (day 1, days 2-4, and day 5) using volumetric subsampling, such that the average of 3 to $550-\mu l$ drops was used to estimate the number of IJs. The cumulative number of IJs emerging from a host by day 5 was calculated as the sum of nematodes collected in all 3 White traps.

Length was measured for day 1 and day 5 IJs from digital photos taken on a compound microscope with a $\times 10$ objective. Slide preparation consisted of $30 \mu \mathrm{l}$ of nematodes in deionized water added to a drop of $\lambda$ carrageenan-water solution $(1 \mathrm{~g} / 150 \mathrm{ml}$; Sigma, St. Louis, Missouri) to reduce IJ movement for more in-focus photos. The lengths for 15 individual nematodes (per host and day) were measured using ImageJ software (National Institutes of Health, Bethesda, Maryland); the averages of these measurements per host per day were used in the data analysis. Some images were out of focus, resulting in day 1 and day 5 measurements being taken for 68 hosts in total.

\section{Fitness effects of IJ size}

Nematodes emerging from 45 hosts in the manipulation of IJ size experiment were used in infectivity assays to assess IJ fitness. Each infectivity assay was paired so that IJs emerging from a single host were exposed to 2 new hosts, either by placing them directly on the dorsum (0 $\mathrm{cm}$ ) or a distance of $1.5 \mathrm{~cm}$ away. Assays were run $24 \mathrm{hr}$ after IJs emerged from their host, with day 1 and day 5 IJs from 5 hosts per each dose and block tested. For each assay, a weighed G. mellonella larva was placed in a screen bag (1-mm mesh) for immobilization. The screen bag was tacked down to cooled soil-agar in a large petri dish $(60 \mathrm{~mm} \times 20 \mathrm{~mm})$. Soil-agar consisted of agar $(1 \mathrm{~g} / 100 \mathrm{ml}$ of distilled water $)$, sprinkled while in a semisolid state with sieved (1-mm), autoclaved soil (Metro Mix 360, Sun Gro Horticulture Distribution Corporation, Bellevue, Washington). Each infectivity host was infected with a $50-\mu l$ drop of deionized water containing IJs that emerged from a single host. The number of IJs in a 50$\mu l$ drop varied for each host, with a mean infective dose ( \pm 1 SE) of 70.41 \pm 2.83 . PI, the assays were kept at $26 \mathrm{C}$ for $96 \mathrm{hr}$, after which they were frozen to stop the progression of the infection. This point is just before the first production of larvae (data not shown). Infected hosts were stored frozen until dissection.

For dissection, host cadavers were transferred to a 60 -mm Petri dish with approximately $1 \mathrm{ml}$ of $0.8 \%$ saline and dissected using forceps. Host tissue was separated from the cuticle, and the head capsule was crushed. More saline was added until the petri dish was one-third full, and the mixture of host materials and saline was put on a rocker at $60 \mathrm{rpm}$ at $37 \mathrm{C}$ for $90 \mathrm{~min}$. This allowed the host connective tissues to break up and release the nematodes, while not damaging nematode bodies. The adult nematodes were counted and sexed. Adult females were easily seen (average $1.5 \mathrm{~cm}$ long), but the adult males and immature nematodes required a drop-by-drop technique to be seen. A drop of the host materialsaline mixture was removed using a $5-\mathrm{ml}$ pipette and placed into a small Petri dish $(35 \mathrm{~mm})$ where it could be examined and possibly diluted to make nematodes $>1 \mathrm{~mm}$ visible amongst the host tissue. This technique was used to look through all the host tissues to obtain a complete tally of females, males, and immature nematodes. From these data, the proportion of successfully infecting nematodes was calculated as the total number of nematodes detected divided by the number in the fitness assay's infective dose. The sex ratio was calculated from sexually mature males and females only and thus represents the operational sex ratio upon successful host colonization; 176 host cadavers were dissected and 99 were found to contain nematodes.

\section{Statistical analysis}

To control for the nested effects of block and host, all analyses included these factors as random effects and the factors of interest as fixed effects using the Mixed Procedure in SAS/STAT ${ }^{\circledast}$ software version 9.1 (SAS Institute, Cary, North Carolina). We performed a mixed model analysis of variance on average IJ length to examine the effect of dose $(20,200$, and $400 \mathrm{IJs} /$ host) and day (1 or 5 post-emergence). To determine whether larger IJ length was associated with the number of emerged IJs, we performed mixed model analyses of covariance (ANCOVAs) on the cumulative number of emerged IJs. Separate analyses were done for day 1 and day 5 to see whether IJ length (a covariate) was correlated with the 


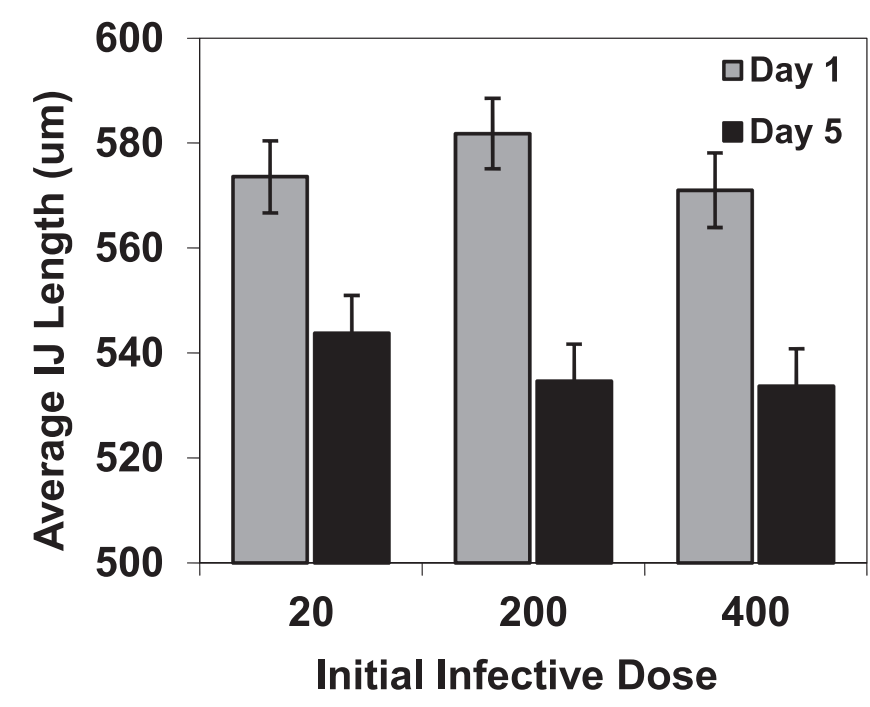

Figure 1. Average length $( \pm 1 \mathrm{SE})$ of $\mathrm{IJ}$ nematodes as a function of infective dose and day of emergence.

number of nematodes that emerged up to that day (the dependent variable). Dose (a 3-level factor) and host mass (a covariate) were included as fixed effects in the model to control for their influence on the number of emerged IJs. None of the interactions among factors and covariates was found to be significant and thus were deleted from the model.

We performed a mixed model logistic regression (Proc Glimmix) to determine whether IJ length or any other factors (dose, day, distance to host, infective dose, mass of the newly infected host) influenced the probability that any nematodes were detected at $96 \mathrm{hr}$ PI in a given host. In cases where nematodes successfully infected a host, we were interested in whether average IJ length influenced the proportion of IJs detected within the host at $96 \mathrm{hr}$ PI, here referred to as "survival." Accordingly, we performed a mixed model ANCOVA on survival to detect whether IJ length and other factors such as the dose (on the original host), day of emergence (day 1 vs. day 5), distance to host ( 0 vs. $1.5 \mathrm{~cm}$ ), fitness assay infective dose, mass of original host, or mass of the fitness assay infected host influenced the success of the infections as measured by proportion of IJs exposed that survived within the new host. We used a similar modeling approach to determine what factors affected the sex ratio of nematodes surviving to $96 \mathrm{hr}$.

\section{RESULTS}

Infective dose did not significantly affect the length of nematodes emerging from a host $\left(F_{2,61}=1.00, P=0.4294\right.$; Fig. 1). In contrast, day of emergence dramatically affected IJ size $\left(F_{1,61}=99.27, P<0.0001\right)$, with early emerging IJs being approximately $7 \%$ longer than those emerging later from the same host (Fig. 1).

We found a significant trade-off between the number and size of offspring IJ emerging from a host (Table I; Fig. 2). For each day of emergence, as hosts produced larger IJs, fewer emerged. In fact, estimates of the slope for each day indicate that each micrometer increase in length resulted in $502 \pm 170$ (mean \pm 1 SE) fewer nematodes emerging by day 1 and $771 \pm 192$ fewer by day 5 (Fig. 2). In addition to the negative effect of IJ length on the number of emerged nematodes, host mass positively affected the number of emerged nematodes, reflecting the greater resource availability in larger hosts, and dose had no significant effect (Table I).

When nematodes were placed directly on the host there was a $50 \%$ increase in the probability of successful infection (nematodes

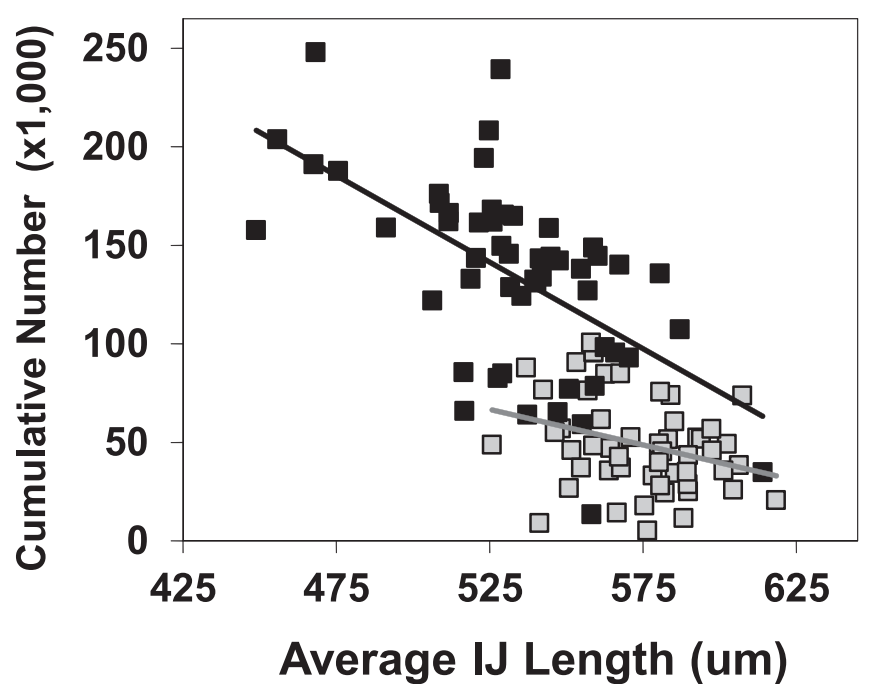

Figure 2. Cumulative number of IJs emerging from a host $(\times 1,000)$ as a function of average IJ length for nematodes emerging on day 1 (gray squares) and day 5 (black squares). For each day, there was a significant trade-off between the number and size of nematodes emerging from a host.

present at $96 \mathrm{hr} \mathrm{PI})$ relative to when IJs were placed $1.5 \mathrm{~cm}$ away from the host $\left(F_{1,126}=8.47, P=0.0043\right)$. None of the other examined variables produced any significant effects.

In the cases where nematodes successfully infected a host, larger IJs had a greater percentage of survival than smaller IJs $\left(F_{1,57}\right.$ $=18.58, P<0.0001$; Fig. 3). Paralleling the result of infection success, nematodes placed directly on the host had higher survival than nematodes placed $1.5 \mathrm{~cm}$ away $\left(F_{1,57}=5.63, P=0.0211\right.$; Fig. 3 circles vs. triangles). There were no significant interactions among these factors, nor did the infective dose applied to the natal host have any effect on the percentage of IJs surviving.

Because IJ length varied with day of emergence (see Fig. 1), we were interested in whether the positive effect of IJ length on survival could be decoupled from the effect of day. So, we examined the relationship between IJ length and survival for each day separately. For day 1 (gray symbols in Fig. 3), IJ length was no longer significant $\left(F_{1,29}=0.21, P=0.6471\right)$, whereas for day 5 (black symbols in Fig 3.), IJ length was highly significant $\left(F_{1,28}=\right.$ $5.65, P=0.0246)$. These results suggest that the smaller day 5 nematodes span a size threshold that is critical for successfully infecting and surviving within the host, whereas the larger day 1 nematodes exceed this threshold (Fig. 3).

TABLE I. Fixed effects from mixed model ANCOVAs on the cumulative number of IJs emerging from a host carcass.

\begin{tabular}{lccrc}
\hline \multicolumn{1}{c}{ Effect } & No. df & Density df & $F$ & $P>F$ \\
\hline Day 1 of emergence & & & & \\
$\quad$ IJ length & 1 & 64 & 8.73 & 0.0044 \\
$\quad$ Infective dose & 2 & 64 & 0.37 & 0.6901 \\
$\quad$ Host mass & 1 & 64 & 3.05 & 0.0857 \\
Day 5 of emergence & & & & \\
$\quad$ IJ length & 1 & 47 & 16.07 & 0.0002 \\
$\quad$ Infective dose & 2 & 47 & 0.15 & 0.8581 \\
$\quad$ Host mass & 1 & 47 & 6.91 & 0.0116 \\
\hline
\end{tabular}




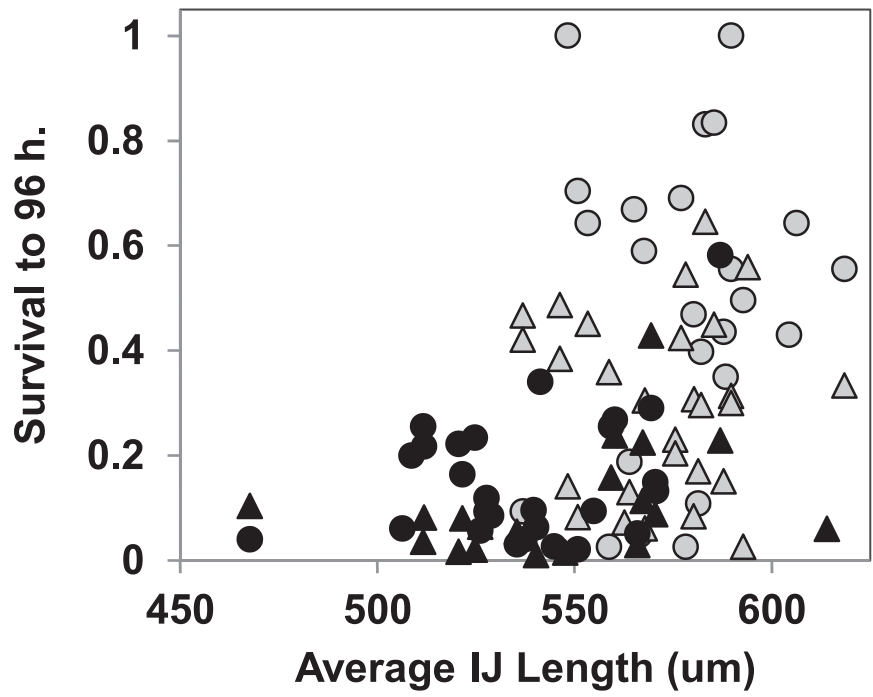

Figure 3. Proportion of nematodes successfully colonizing and surviving to $96 \mathrm{hr}$ PI within a caterpillar host as a function of average IJ length. IJs emerged from their natal host either on day 1 (gray) or day 5 (black) PI and then were placed either directly on the assay hosts $0 \mathrm{~cm}$ (circles) or $1.5 \mathrm{~cm}$ (triangles) away.

Sex ratio was significantly affected by day of emergence $\left(F_{1,58}=\right.$ 4.50, $P=0.0382)$. Specifically, although the sex ratio was not significantly different from 50:50 on day 1 , on day 5 there was a significant bias toward females (Fig. 4). The distance to the host did not affect the sex ratio $\left(F_{1,58}=1.91, P=0.1718\right)$, suggesting that the 2 sexes do not differ in their host-finding strategies or locomotive abilities. In addition, there were no significant interactions between day and distance $\left(F_{1,58}=1.42, P=0.2375\right)$ or effects of IJ length or dose (of either the original or the fitness assay host) on sex ratio.

\section{DISCUSSION}

Environmental effects can lead to life-history trade-offs that can affect future generations (e.g., Bashey, 2006). For parasites, environmental effects in 1 host may affect infection success in a new host, resulting in trans-host effects. Our work shows that the size of nematodes emerging from the carcass of an insect host declines as the infection progresses (Fig. 1). Furthermore, we found that the greater the number of nematodes emerging from an insect host, the smaller the average length of each individual (Fig. 2). Both the decline of IJ size with time and the trade-off between the size and number of emerging nematodes indicate that resource availability inside the host carcass is fixed and becomes depleted with time. The consequence of this resource limitation affects not only the number of propagules released into the environment but also the fitness of these propagules. We found that larger and earlier emerging nematodes had a greater success at infecting and surviving in a new host (Fig. 3). Moreover, fitness differences between the sexes were observed with a shift in the operational sex ratio, as late emerging nematodes showed a significant female bias (Fig. 4).

Our finding of no effect of initial infective dose on the size of emerging IJs (Fig. 1) contrasts those of Selvan et al. (1993), who saw a drop in IJ size as the dose increased from 20 to 200 nematodes/larval host. Selvan et al. (1993) also saw an increase in

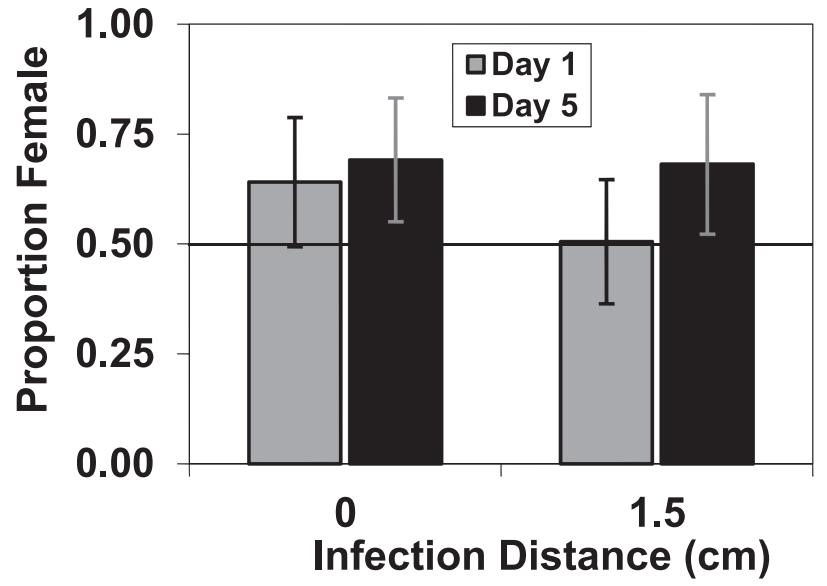

Figure 4. Sex ratio (given as proportion female) of nematodes present at $96 \mathrm{hr}$ PI as a function of whether IJs were applied directly on the host (distance $0 \mathrm{~cm}$ ) or $1.5 \mathrm{~cm}$ away and the day of emergence of these IJs from their natal host. The $95 \%$ confidence intervals are shown.

the number of emerging nematodes with infective dose, although we did not (Table I). The cause of these discrepancies is unknown but could be due to a difference in source nematode and host stocks used. In our population, the mass of the host is a more important predictor of the number of nematodes produced than the initial dose (Table I). Nevertheless, our work does support a general pattern seen in steinermatid nematodes that IJ size decreases over the first week of emergence (Nguyen and Smart, 1995). We also establish that a trade-off between the number and size of IJs that emerge from a host occurs (Fig. 2). This phenotypic trade-off confirms that more nematodes emerging from a given sized carcass comes at a cost of their size. For these nematodes, size and number traits may be linked evolutionarily such that changes in size result in changes in number and vice versa. Indeed, in an experiment where selection was imposed on the numbers of nematodes emerging from a host, associated changes in IJ size occurred (Bashey and Lively, 2009).

The genetic contribution of a subpopulation to the next generation depends not only on the number of propagules produced but also critically on the fitness of these propagules. Our fitness assays showed that larger emerging nematodes had a higher probability of successfully infecting a new host (Fig. 3). Thus, even in the benign laboratory environment, subpopulations producing larger IJs could be more successful, despite producing fewer IJs. In nature, predators, desiccation, or reduced host availability in the soil environment could accentuate the benefits of larger IJ size. Similar size-mediated effects on transmission success have been found in an acanthocephalan parasite (Steinauer and Nickol, 2003). In addition, smaller emerging parasitoids have lower fecundity and dispersal capability (Ellers et al., 1998; Olson and Andow, 1998; Allen and Hunt, 2001). Taken together with our study, these findings suggest that size may be an important general mechanism altering parasite fitness and population dynamics.

We hypothesized that fitness consequences of IJ size may be due to locomotor ability. However, the result of larger individuals having a greater probability of successfully infecting and maturing within a host occurred whether the IJs were directly applied to a host or had to locate the host from $1.5 \mathrm{~cm}$ away (Fig. 
3). Thus, we conclude that larger IJs have a fitness advantage independent of their ability to disperse effectively. Possibly, greater size provides nematodes with a growth advantage in the new host (cf. Fredensborg and Poulin, 2005) that may then facilitate survival. Alternatively, larger nematodes have been shown to have larger bacteria storage vesicles (Flores-Lara et al., 2007) that may allow them to store and release more bacteria and cause a faster disabling of the insect immune system (Richards and Goodrich-Blair, 2009). The nematode cuticle and surface coat proteins also suppress the insect immune system (Wang and Gaugler, 1999; Brivio et al., 2002). Because larger nematodes have larger surface areas, our results may be due to greater immune suppression by these factors. Thus, although size may not enhance dispersal, it may give a growth or immune system evasion advantage, thereby enhancing survival.

Although the size-number trade-off was confirmed in both early and late emerging nematodes, the impact of size on survival cannot be entirely decoupled from emergence day because nematode size was highly correlated with day of emergence (Figs. 1, 3). Intriguingly, 2 studies have shown that late emerging $S$. carpocapsae are more successful at establishing within a host than early emerging nematodes (Lewis and Gaugler, 1994; Alsaiyah et al., 2009). Unfortunately, neither of these studies measured IJ size, so it is not possible to know whether increased infectivity of later emerging nematodes occurs only when there are minimal differences in size, or whether size and emergence effects differ across populations. Nevertheless, the smaller size and lower fitness of later emerging nematodes that we find parallels the results of other organisms living in a seasonal environment. Often, later hatching individuals have less time or resources available to grow or build fat reserves; consequently, they have a lower probability of surviving the winter or lower fecundity the following year (Sinervo and Doughty, 1996; Einum and Fleming, 2000b; Cooch, 2002).

Emergence day also affected the observed sex ratio, as we observed a shift from a 50:50 sex ratio on day 1 to a female-biased sex ratio on day 5. Fujimoto et al. (2007) also saw a female-biased sex ratio of late emerging $S$. carpocapsae (strain All). However, 2 other studies using the same strain showed an overall femalebiased sex ratio that was greater for early emerging nematodes (Lewis and Gaugler, 1994; Alsaiyah et al., 2009). These studies suggest that operational sex ratio is quite variable across populations of this species. Differences between the sexes in host seeking behavior has been suggested as a possible mechanism for shifting sex ratios (Grewal et al., 1993), but we found no evidence for behavioral differences between male and females in our study, because sex ratio did not vary with infection distance (Fig. 4). Shifts in the primary sex ratio could occur by local mate competition as female-biased sex ratios are favored in more inbred populations (Hamilton, 1967; Alsaiyah et al., 2009). Because nematodes may undergo multiple generations within a host, it is possible that later emerging nematodes arise from a more inbred population than early emerging nematodes. In addition, Fujimoto et al. (2007) found that late emerging IJs were less likely to disperse than early emerging IJs, thereby increasing the probability of inbreeding in a new host. Alternatively, the female bias in late emerging nematodes could be due to higher survival of late emerging females relative to males. Higher male mortality is thought to be the cause of female-biased sex ratios in many acanthocephalan and nematode parasites (Roche and
Patrzek, 1966; Poulin, 1997). However, it is unclear why differential mortality would be present only in late emerging nematodes. One unexplored possibility may be that late emerging male IJs are smaller than females and are thus below a critical size threshold.

We have demonstrated a trade-off between the number and size of nematodes emerging from a host carcass. This trade-off is meaningful because we also demonstrate that small nematodes have reduced infection success and survival in a new host. Small nematodes were more likely to emerge later in the time course of the infection and these later emerging nematodes showed a female-biased sex ratio in the new host. These results indicate that as resource levels drop in the natal host carcass, investment in the number or size of male offspring may be reduced. In conclusion, our study illustrates the importance of the host environment to the fitness of parasites and the potential for trans-hosts effects to alter the ecological and evolutionary dynamics of parasite populations.

\section{ACKNOWLEDGMENTS}

We thank C. Lively, C. Sears, and S. Rangel for advice and logistical support. M. T. thanks the Moczek laboratory, D. Maestripieri, and J. Hammond for advice and encouragement. K. King, J. M. Miller, and M. Greischar provided useful feedback on the manuscript. Funding was provided by National Science Foundation grants DEB-0515832 and DEB0919015 to C. Lively and F.B. and a Howard Hughes Medical Institute Capstone Grant to M. O. Therese.

\section{LITERATURE CITED}

Allen, G. R., And J. Hunt. 2001. Larval competition, adult fitness, and reproductive strategies in the acoustically orienting ormiine Homotrixa alleni (Diptera: Tachinidae). Journal of Insect Behavior 14: 283 297.

Alsaiyah, M. A. M., L. Ebssa, A. Zenner, K. M. O’Callaghan, and C. T. Griffin. 2009. Sex ratios and sex-biased infection behaviour in the entomopathogenic nematode genus Steinernema. International Journal for Parasitology 39: 725-734.

Bashey, F. 2006. Cross-generational environmental effects and the evolution of offspring size in the Trinidadian guppy Poecilia reticulata. Evolution 60: 348-361.

, And C. M. Lively. 2009. Group selection on population size affects life-history patterns in the entomopathogenic nematode Steinernema carpocapsae. Evolution 63: 1301-1311.

, L. T. Morran, and C. M. Lively. 2007. Coinfection, kin selection, and the rate of host exploitation by a parasitic nematode. Evolutionary Ecology Research 9: 947-958.

Bedhomme, S., P. Agnew, C. Sidobre, and Y. Michalakis. 2003. Sexspecific reaction norms to intraspecific larval competition in the mosquito Aedes aegypti. Journal of Evolutionary Biology 16: 721730 .

Brivio, M. F., M. Pagani, and S. Restelli. 2002. Immune suppression of Galleria mellonella (Insecta, Lepidoptera) humoral defenses induced by Steinernema feltiae (Nematoda, Rhabditida): Involvement of the parasite cuticle. Experimental Parasitology 101: 149-156.

Campbell, J. F., and R. Gaugler. 1993. Nictation behavior and its ecological implications in the host search strategies of entomopathogenic nematodes (Heterhabditidae and Steinernematidae). Behaviour 126: $155-169$.

, AND H. KAYA. 1999. How and why a parasitic nematode jumps. Nature 397: 485-486.

, E. E. Lewis, S. P. Stock, S. Nadler, and H. Kaya. 2003. Evolution of host search strategies in entomopathogenic nematodes. Journal of Nematology 35: 142-145.

Cipollini, M. L. 1991. Female-biased sex-ratios in response to increased density in a bruchid seed predator: A consequence of local mate competition. Oikos 60: 197-204. 
Cooch, E. G. 2002. Fledging size and survival in snow geese: Timing is everything (or is it?). Journal of Applied Statistics 29: 143-162.

Einum, S., AND I. A. Fleming. 2000a. Highly fecund mothers sacrifice offspring survival to maximize fitness. Nature 405: 565-567.

— offspring in Atlantic salmon (Salmo salar). Evolution 54: 628-639.

Eitam, A., L. Blaustein, and M. Mangel. 2005. Density and intercohort priority effects on larval Salamandra salamandra in temporary pools. Oecologia 146: 36-42.

Ellers, J., J. J. M. Van Alphen, and J. G. Sevenster. 1998. A field study of size-fitness relationships in the parasitoid Asobara tabida. Journal of Animal Ecology 67: 318-324.

Fleming, I. A., AND M. R. Gross. 1990. Latitudinal clines: A trade-off between egg number and size in Pacific salmon. Ecology 71: 1-11.

Flores-Lara, Y., D. Renneckar, S. Forst, H. Goodrich-Blair, and P. STOCK. 2007. Influence of nematode age and culture conditions on morphological and physiological parameters in the bacterial vesicle of Steinernema carpocapsae (Nematoda: Steinernematidae). Journal of Invertebrate Pathology 95: 110-118.

Fox, C. W., AND M. E. CZESAK. 2000. Evolutionary ecology of progeny size in arthropods. Annual Review of Entomology 45: 341-369.

Fredensborg, B. L., AND R. Poulin. 2005. Larval helminths in intermediate hosts: Does competition early in life determine the fitness of adult parasites? International Journal for Parasitology 35: 1061-1070.

Fujimoto, A., E. E. Lewis, G. Cobanoglu, and H. Kaya. 2007. Dispersal, infectivity and sex ratio of early- or late-emerging infective juveniles of the entomopathogenic nematode Steinernema carpocapsae. Journal of Nematology 39: 333-337.

Grewal, P. S., S. Selvan, E. E. Lewis, and R. Gaugler. 1993. Male insect-parasitic nematodes: A colonizing sex. Experientia 49: 605608.

Hamilton, W. D. 1967. Extraordinary sex ratios. Science 156: 477-488.

Herreras, M. V., F. E. Montero, D. J. Marcogliese, J. A. Raga, and J. A. Balbuena. 2007. Phenotypic tradeoffs between egg number and egg size in three parasitic anisakid nematodes. Oikos 116: 1737-1747.

Hirschberger, P. 1999. Larval population density affects female weight and fecundity in the dung beetle Aphodius ater. Ecological Entomology 24: 316-322.

IzrayleVICH, S., AND U. Gerson. 1996. Sex allocation by a mite parasitic on insects: Local mate competition, host quality and operational sex ratio. Oecologia 108: 676-682.

Jakobsson, A., AND O. ERIKSSON. 2000. A comparative study of seed number, seed size, seedling size and recruitment in grassland plants Oikos 88: 494-502.

LACK, D. 1947. The significance of clutch-size. Ibis 89: 302-352.

Lebreton, S., C. Chevrier, and E. Darrouzet. 2010. Sex allocation strategies in response to conspecifics' offspring sex ratio in solitary parasitoids. Behavioral Ecology 21: 107-112.

Lewis, E. E., AND R. Gaugler. 1994. Entomopathogenic nematode (Rhabdita: Steinernematidae) sex ratio relates to foraging strategy. Journal of Invertebrate Pathology 64: 238-242.

Little, T., J. Birch, P. VAle, And M. Tseng. 2007. Parasite transgenerational effects on infection. Evolutionary Ecology Research 9: 459469.

LOKER, E. S. 1983. A comparative study of the life-histories of mammalian schistosomes. Parasitology 87: 343-369.

Lowrie, F. M., J. M. Behnke, and C. J. Barnard. 2004. Densitydependent effects on the survival and growth of the rodent stomach worm Protospirura muricola in laboratory mice. Journal of Helminthology 78: 121-128.

Mappes, T., AND E. KosKela. 2004. Genetic basis of the trade-off between offspring number and quality in the bank vole. Evolution 58: 645650.

Milonas, P. G. 2005. Influence of initial egg density and host size on the development of the gregarious parasitoid Bracon hebetor on three different host species. Biocontrol 50: 415-428.
Nagelkerke, C. J., and M. W. Sabelis. 1998. Precise control of sex allocation in pseudo-arrhenotokous phytoseiid mites. Journal of Evolutionary Biology 11: 649-684.

Nguyen, K. B., and G. C. J. Smart. 1995. Morphometrics of infective juveniles of Steinernema spp. and Heterorhabditis bacteriophora (Nemata: Rhabditida). Journal of Nematology 27: 206-212.

Olson, D. M., AND D. A. Andow. 1998. Larval crowding and adult nutrition effects on longevity and fecundity of female Trichogramma nubilale Ertle and Davis (Hymenoptera: Trichogrammatidae). Environmental Entomology 27: 508-514.

Peters, A. 1996. The natural host range of Steinernema and Heterorhabditis spp. and their impact on insect populations. Biocontrol Science and Technology 6: 389-402.

Popiel, I. 1989. Infective juvenile formation in the insect parasitic nematode Steinernema feltiae. Parasitology 99: 77-81.

Poulin, R. 1995. Clutch size and egg size in free-living and parasitic copepods: A comparative analysis. Evolution 49: 325-336.

. 1997. Population abundance and sex ratio in dioecious helminth parasites. Oecologia 111: 375-380.

Qui, L., AND R. A. Bedding. 2000a. Energy metabolism and its relation to survival and infectivity of infective juveniles of Steinernema carpocapsae under aerobic conditions. Nematology 2: 551-559.

, AND - 2000b. Energy metabolism and survival of the infective juveniles of Steinernema carpocapsae under oxygen-deficient conditions. Journal of Nematology 32: 271-280.

Richards, G. R., and H. Goodrich-Blair. 2009. Masters of conquest and pillage: Xenorhabdus nematophila global regulators control transitions from virulence to nutrient acquisition. Cellular Microbiology 11: $1025-1033$.

Roche, M., and D. Patrzek. 1966. Female to male ratio (FMR) in hookworm. Journal of Parasitology 52: 117-121.

Ryder, J. J., And C. T. Griffin. 2002. Density-dependent fecundity and infective juvenile production in the entomopathogenic nematode, Heterorhabditis megidis. Parasitology 125: 83-92.

Sandland, G. J., and C. P. Goater. 2000. Development and intensity dependence of Ornithodiplostomum ptychocheilus metacercariae in fathead minnows (Pimephales promelas). Journal of Parasitology 86: 1056-1060.

Selvan, S., J. F. Campbell, and R. Gaugler. 1993. Density-dependent effects on entomopathogenic nematodes (Heterorhabditidae and Steinernematidae) within an insect host. Journal of Invertebrate Pathology 62: 278-284.

Sinervo, B., AND P. Doughty. 1996. Interactive effects of offspring size and timing of reproduction on offspring reproduction: Experimental, maternal, and quantitative genetic aspects. Evolution 50: 1314-1327.

Smith, C. C., and S. D. Fretwell. 1974. The optimal balance between size and number of offspring. American Naturalist 108: 499-506.

StAnton, M. L. 1984. Seed variation in wild radish: Effect of seed size on components of seedling and adult fitness. Ecology 65: 1105-1112.

Steinauer, M. L., AND B. B. NicKOL. 2003. Effect of cystacanth body size on adult success. Journal of Parasitology 89: 251-254.

TSENG, M. 2006. Interactions between the parasite's previous and current environment mediate the outcome of parasite infection. American Naturalist 168: 565-571.

Wall, R., AND M. BegON. 1987. Individual variation and the effects of population-density in the grasshopper Chorthippus brunneus. Oikos 49: 15-27.

Wang, Y., And R. Gaugler. 1999. Steinernema glaseri surface coat protein suppresses the immune response of Popillia japonica (Coleoptera: Scarabaeidae) larvae. Biological Control 14: 45-50.

White, G. F. 1927. A method for obtaining nematode larvae from cultures. Science 66: 302-303.

Zervos, S. 1988. Evidence for population self-regulation, reproductive competition and arrhenotoky in a thelastomatic nematode of cockroaches. Parasitology 96: 369-379. 